Supporting Information for

\title{
Spatial Extent of Future Changes in the Hydrologic Cycle Components in Ganga Basin using Ranked CORDEX RCMs
}

Jatin Anand ${ }^{1}$, Manjula Devak ${ }^{1}$, Ashvani Kumar Gosain ${ }^{1}$, Rakesh Khosa ${ }^{1}$ and Chandrika Thulaseedharan Dhanya ${ }^{1}$

${ }^{1}$ Department of Civil Engineering, Indian Institute of Technology Delhi, New Delhi-110016, India.

Correspondence to: Dr. Chandrika Thulaseedharan Dhanya (dhanya@ civil.iitd.ac.in)

Contents of this file

Fig. S1, Fig. S2 and Fig. S3

10

15

20

25 


\section{Introduction}

This supporting information provides the figures supporting the analysis presented in main article.

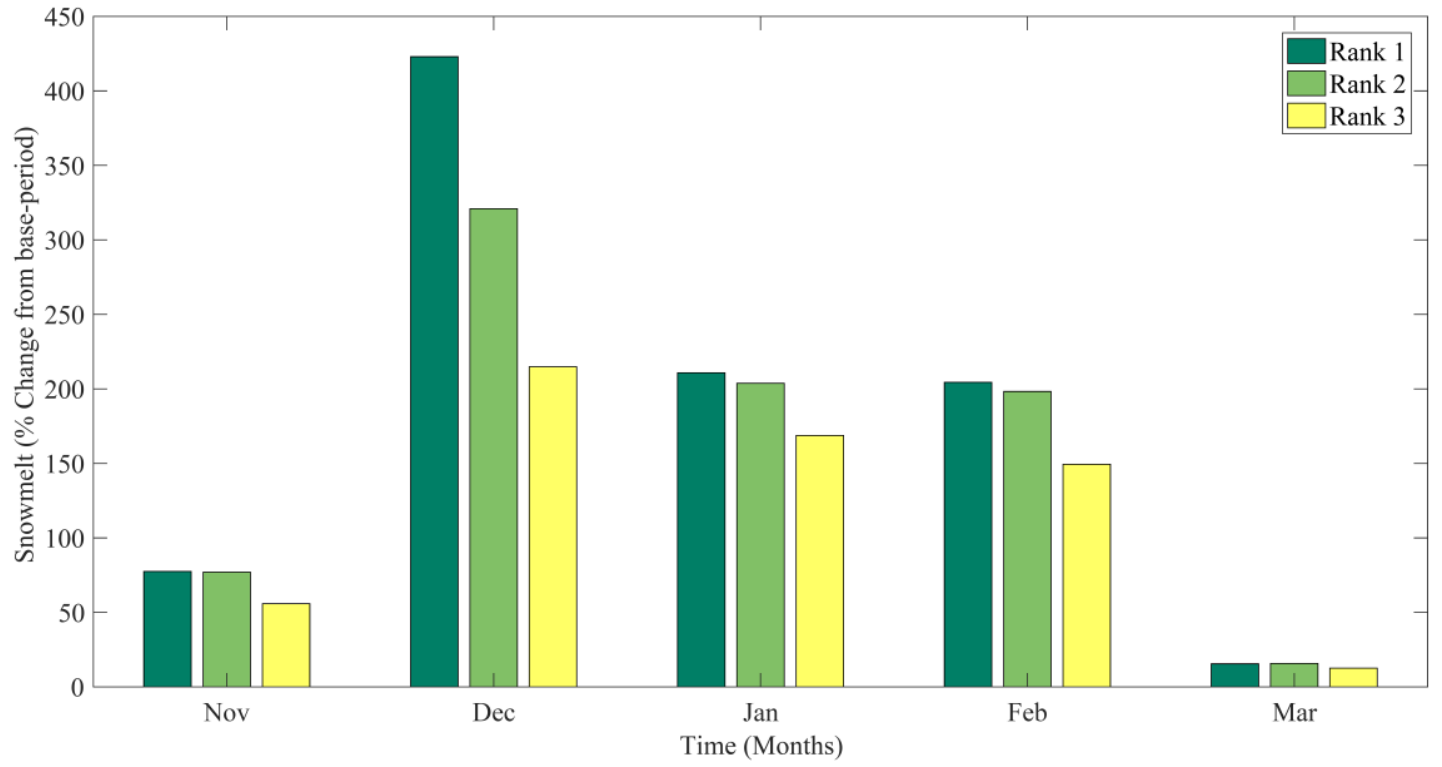

Fig. 1. Percentage change in simulated projected changes in average monthly snowmelt at Rishikesh for ranked RCMs for the period 20121-2100. 

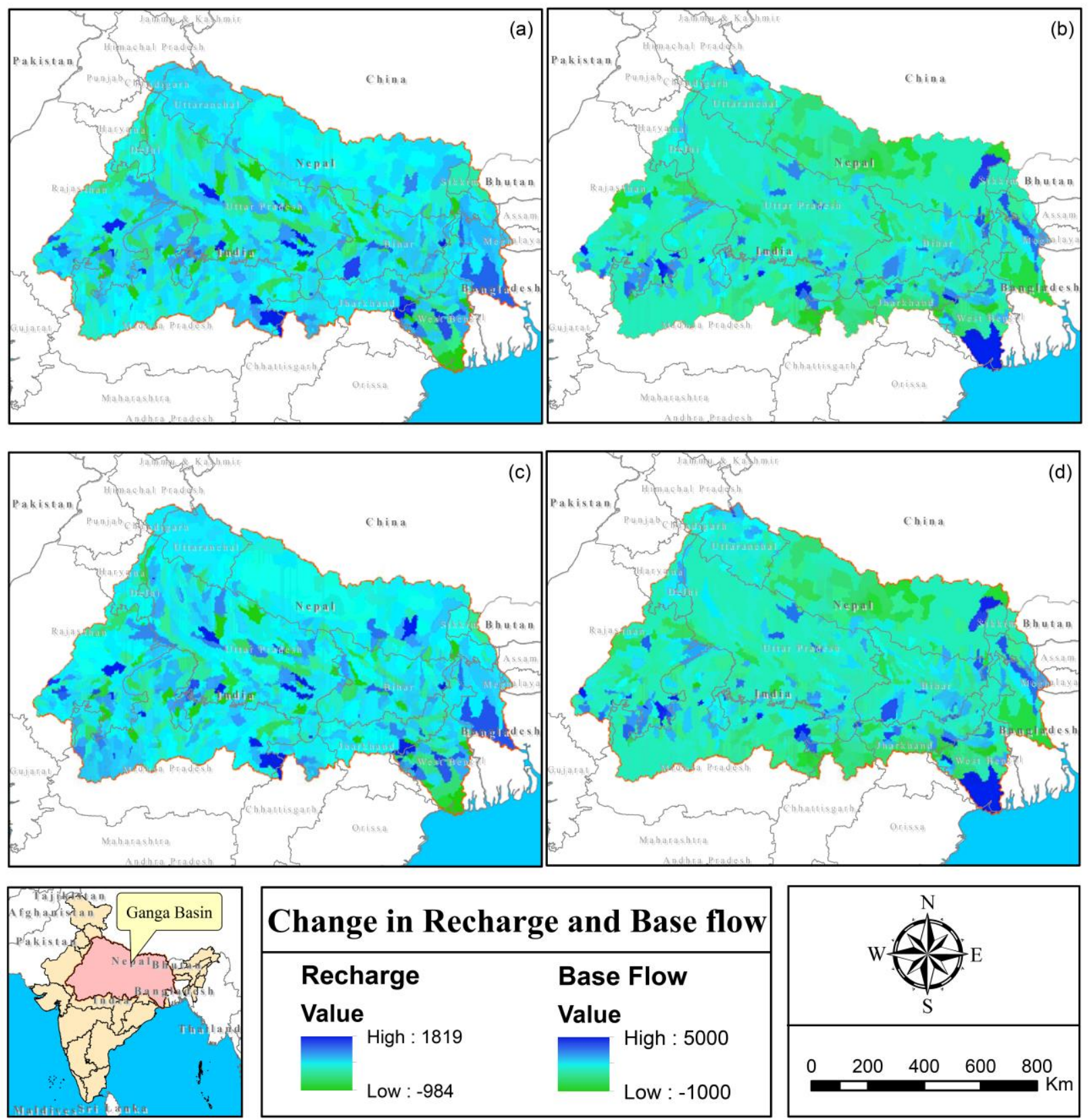

Fig. S2. Change in Recharge for the period (a) 2021-60 and (c) 2061-2100; and Base flow for the period (b) 2021-60 and (d) 2061-2100 in Ganga river basin projected by RCA4 (MIROC). 

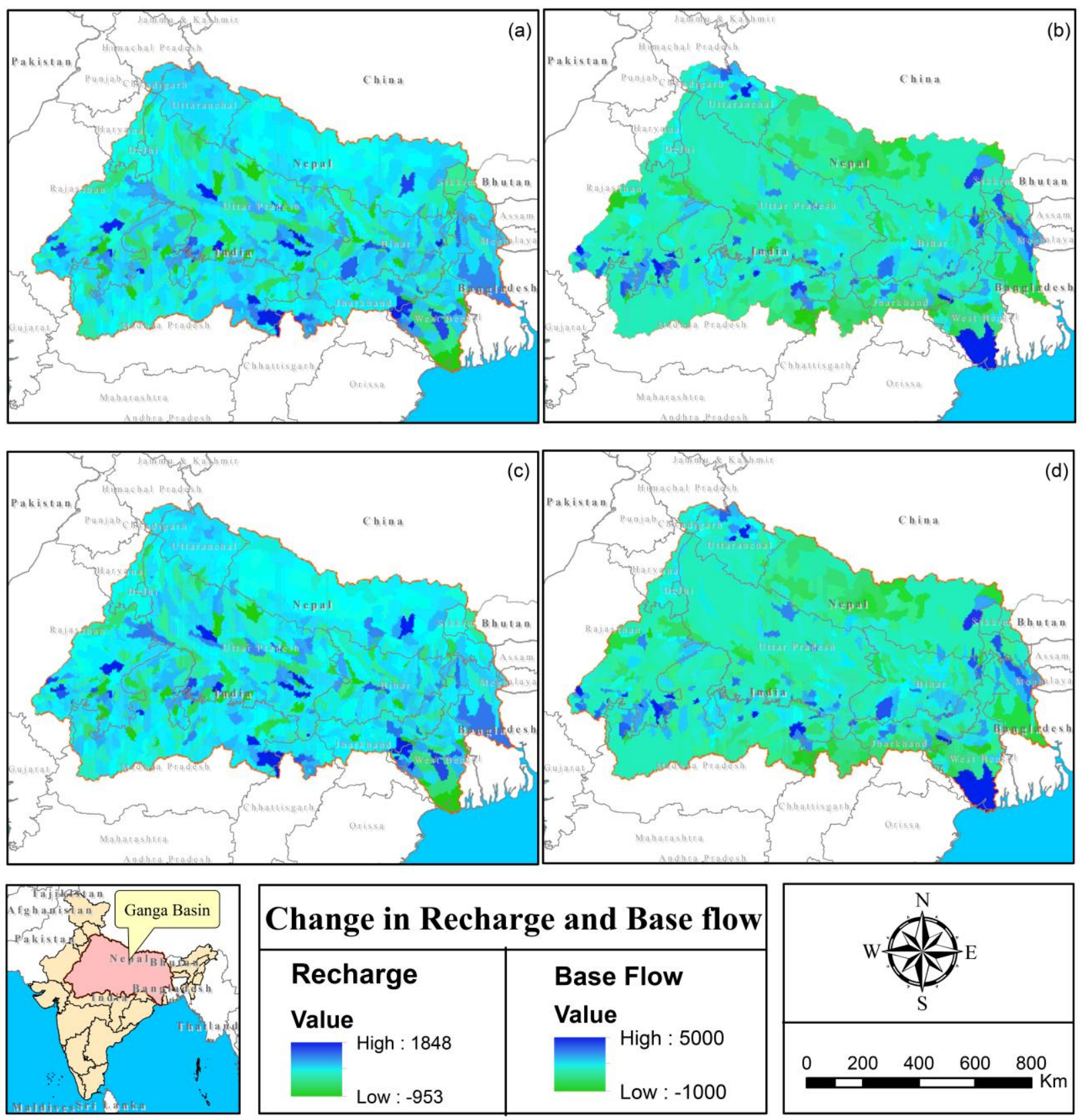

Fig. S3. Change in Recharge for the period (a) 2021-60 and (c) 2061-2100; and Base flow for the period (b) 2021-60 and (d) 2061-2100 in Ganga river basin projected by RCA4 (ICHEC). 